\title{
The Application of Chinese Traditional Food Culture in the Teaching of Korean Students
}

\author{
Bei Zhang', Yanru Dai ${ }^{2}$, Huiyong Zheng ${ }^{3}$ \\ 'Xi'an University of Finance and Economics, Xi' an 710100, Shaanxi \\ ${ }^{2}$ Xi' an Jiaotong University, Xi'an 710048, Shaanxi \\ ${ }^{3}$ Xi'an Zimo Translation Service Co., Ltd, Xi'an 710061, Shaanxi
}

\begin{abstract}
With the gradual improvement of China's economic and political status on the international stage, the time-honored, extensive and profound Traditional Chinese culture has more and more bloomed its unique Oriental charm. More and more international students come to Study in China to learn about the fine traditional Chinese culture. This paper will take The Korean students as the research object, analyze the traditional Chinese food culture, and carry out the teaching research on the Korean students' food culture.
\end{abstract}

Keywords: Chinese Traditional Food Culture; South Korean Students; Teaching

\section{Chinese traditional food culture is the best entry point for learning Chinese excellent traditional culture}

The excellent Chinese traditional culture contains rich philosophical thoughts, moral sentiments, values, aesthetic character, artistic taste, dialectical thinking and scientific wisdom. It is a precious spiritual deposit of the Chinese nation. Facing the extensive and profound Chinese excellent traditional culture, international students in China have too many things to learn, but after all, they have limited time and cannot cover everything. "Focus on the big place, start with the small place." We believe that learning Chinese traditional culture also needs to start small, step by step, from easy to difficult. Traditional Chinese food culture is the best entry point. Confucius said: Food and color are also. "Food is the heaven for the people", and food is indispensable. From ancient times to the present, food is too important. From resolving hunger, to eating well, to eating healthy, we strive hard. In fact, food can not only satisfy hunger and meet people's survival needs, but food is also a carrier. It carries unique cooking techniques, and even carries the geography, history, customs and culture of a nation. The traditional Chinese food culture has always had a strong fulcrum in the cultural exchanges and collisions with other countries in the world. This enables her to continuously improve and develop in the process of learning from others' strengths, and has unfailing vitality. This fulcrum is the characteristics of excellent traditional culture, which is the basic connotation that Chinese food culture needs to explore. Therefore, the learning and experience of Chinese traditional food culture not only helps to learn Chinese language, but also helps to deepen the understanding of Chinese excellent traditional culture. In terms of its deep connotation, Chinese food culture can be summarized into four words: essence, beauty, affection and courtesy. These four words reflect the unique cultural connotations contained in the dietary quality, aesthetic experience, emotional activities, and social functions in the process of dietary activities, and also reflect the close connection between dietary culture and Chinese excellent traditional culture. It can be seen that food culture belongs to the category of material culture, which is both cultural and practical, so it is the most attractive to international students. Therefore, many domestic colleges and universities have opened food culture practice courses for international students.

\section{The foreign exchange of traditional Chinese food culture is the best path for "people- to-people friendship" and "heart-to-heart communication"}

Today's world is changing with each passing day and has entered the era of globalization. Peace and development have become the themes of the times. Every country is part of a community with a shared future for mankind, and every country cannot develop without other countries. The relations between countries are closer and interdependent. Equality, mutual benefit, and win-win cooperation are the foundation of relations between countries. The Chinese government advocates extensive sharing 
and exchanges in various fields such as science, education, culture, and health, which is conducive to the mutual understanding, mutual trust and respect of the people of the countries along the route, and sharing of a harmonious, peaceful and prosperous life. The national conditions of different countries are not the same. Only by building a bond of communication between people, letting people go from acquaintance to knowing, from knowing to trust, from trust to close cooperation, and establishing sincere mutual benefit, mutual trust and win-win cooperation, is the relationship between state and state. Towards a solid foundation. "The relationship between nations lies in the closeness of the people, and the closeness of the people lies in the connection of hearts." The national systems and religious beliefs of different countries are not the same, so all ethnic groups must respect each other, seek common ground while reserving differences, and find similarities in different styles - Cultural exchange is an entry point. Chinese traditional food culture is an important part of China's excellent traditional culture and the crystallization of the wisdom of the Chinese nation. Offering food culture practice courses for international students in China, and building an experiential learning exchange platform for traditional Chinese food culture, so that international students in China not only appreciate traditional Chinese food culture, but also learn traditional Chinese food and cooking techniques on the exchange platform, which is more helpful Yu came to China to spread Chinese culture around the world. On the world stage, the traditional Chinese culture and the culture of all nations in the world, "Everyone has its own beauty, the beauty of the beauty, the beauty of the same, the world is the same."

\section{Ways to apply Chinese traditional food culture to Korean students teaching}

\subsection{Diversified cultural display}

By using objects, pictures, videos and other forms, it will be more intuitive, vivid and interesting, and it will be easier to attract students' attention, increase students' interest in learning, and achieve better teaching effects. In addition, the rich and diverse content of Chinese food culture, the differences in food customs in various parts of China, and the Chinese food etiquette formed by thousands of years of cultural precipitation, make it difficult for foreign students to understand. If you use multimedia to teach students Demonstrating and introducing Chinese food culture will enable students to experience the life situation in China immersively, so as to better understand the Chinese cultural thoughts contained in Chinese food culture. For example: when learning about the seating arrangement in Chinese food etiquette culture, teachers can directly use PPT to show the seat map, combined with pictures to explain the deep cultural connotation, so that students can more intuitively understand the seating arrangement of the Chinese banquet.

\subsection{Task-based cultural teaching}

In the foreign Chinese food etiquette and culture class, teachers can adopt a task-based teaching method. According to specific teaching content and learning tasks, students are divided into several groups, and the learning tasks are assigned to each group of students. In the classroom, the results are displayed in the form of speeches, explanations, performances, etc., and the teacher comments, supplements and summarizes the students' performance. For example: when explaining the etiquette of Chinese tableware, the teacher can divide the students into four groups. Each group is responsible for the etiquette and taboos of one or two Chinese tableware, and compare it with the tableware etiquette of their own country. The tasks of the group are further subdivided to ensure that each member participates in the completion of the task. In the end, the group summarizes and discusses and analyzes the collected data. Each group takes turns to display the results in the class, and the teacher gives feedback and summary after the display.

\subsection{Performing cultural simulation}

In the performance process, the teacher acts as a guide, corrector and demonstrator, not only to create a cultural scene, but also to give timely feedback during the performance. For example: when learning dining etiquette, the teacher first introduces the basic knowledge of Chinese dining etiquette, displays the content to be performed on the PPT, and discusses the content of the performance with the students. Before the end of get out of class, the teacher organizes the students to arrange the scenes for the performance activities in the next class, and prepare the props needed for the performance. In the second class, the teacher organizes students to perform. During the performance, the teacher should observe the students' use and understanding of language knowledge and give timely feedback. By simulating real cultural scenes, students can have a more accurate and in-depth understanding of Chinese dining etiquette and dining culture.

\section{Conclusion}

All in all, Chinese traditional food culture is an important part of Chinese excellent traditional culture. It is the best entry point for international students to learn Chinese excellent traditional culture. It is the best way to achieve "people-to-people friendship" and "heart-to-heart", which is helpful to cultivate Compound talents with cross-cultural communication skills. Through multiple channels such as diversified cultural display, task-based cultural teaching, and performance-based cultural simulation, Korean students can truly understand the cultural heritage behind our country's food.

\section{References}

1 Jing C, Jiang-Feng WU, She-Dan L. Application of Sandwich Teaching Method in the Teaching of Human Anatomy for Foreign Students [J]. Education Teaching Forum, Vol.28, No.5, PP. 1-8, 2018.

2 Yan-Wei W, Yi-Ping Z. A qualitative study of the key factors in the teaching of culture-based course to foreign students [J]. Journal of Yunnan Normal University (Teaching and Research on Chinese as a Foreign Language), Vol.22, No.3, PP. 1091- 
1093, 2018.

3 Yu-Lin L, School A. Research on the Problem of "Chinese Characters Difficult to Learn" in the Teaching of Foreign Students: A Case Study of International Students from American and Lao in Pu'er College [J]. Journal of Yunnan Open University, Vol.36, No.3, PP. 98-100, 2019.

4 Min-Fei G, Marxism SO. On the Application of Simulated Teaching Method in the Teaching of Chinese Traditional Culture [J]. Journal of Qiqihar University (Philosophy \& Social ence Edition), Vol.16, No.4, PP. 105-108, 2019.

5 Yuan Q. The Application of Chinese Excellent Traditional Culture in the Ideological and Political Education of Higher Vocational Colleges [J]. Education Teaching Forum, Vol.22, No.8, PP. 2806-2808, 2018. 